\title{
Inorganic Colloidal Electrolyte for Highly Robust Zinc-Ion Batteries
}

Cite as

Nano-Micro Lett.

(2021) 13:69

Jiawei Gao ${ }^{1}$, Xuesong Xie ${ }^{1}$, Shuquan Liang ${ }^{1,3}$, Bingan $\mathrm{Lu}^{2}{ }^{凶}$, Jiang Zhou ${ }^{1,3} \bowtie$

Received: 19 November 2020

Accepted: 13 January 2021

Published online: 11 February 2021

(C) The Author(s) 2021

\section{HIGHLIGHTS}

- The $\mathrm{Zn} / \mathrm{MnO}_{2}$ cell with inorganic colloidal electrolyte demonstrates unprecedented durability over 1000 cycles.

- For the cathode, the presence of the protective film can inhibit the dissolution of manganese element and the formation of irreversible by-products.

- For the anode, it can reduce the corrosion and de-solvation energy, inhibit the growth of dendrite and irreversible by-products.

ABSTRACT Zinc-ion batteries (ZIBs) is a promising electrical energy storage candidate due to its eco-friendliness, low cost, and intrinsic safety, but on the cathode the element dissolution and the formation of irreversible products, and on the anode the growth of dendrite as well as irreversible products hinder its practical application. Herein, we propose a new type of the inorganic highly concentrated colloidal elec-

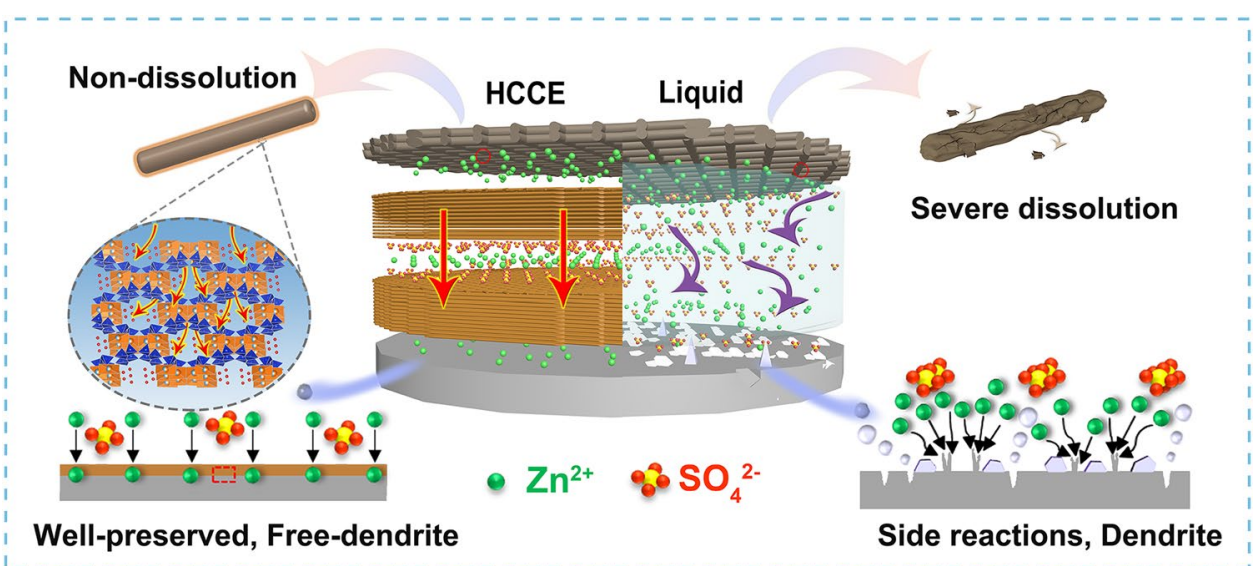
trolytes (HCCE) for ZIBs promoting simultaneous robust protection of both cathode/anode leading to an effective suppression of element dissolution, dendrite, and irreversible products growth. The new HCCE has high $\mathrm{Zn}^{2+}$ ion transference number $(0.64)$ endowed by the limitation of $\mathrm{SO}_{4}{ }^{2-}$, the competitive ion conductivity $\left(1.1 \times 10^{-2}\right.$ $\mathrm{S} \mathrm{cm}^{-1}$ ) and $\mathrm{Zn}^{2+}$ ion diffusion enabled by the uniform pore distribution $(3.6 \mathrm{~nm})$ and the limited free water. The $\mathrm{Zn} / \mathrm{HCCE} / \alpha-\mathrm{MnO}_{2}$ cells exhibit high durability under both high and low current densities, which is almost $100 \%$ capacity retention at $200 \mathrm{~mA} \mathrm{~g}^{-1}$ after $400 \mathrm{cycles}\left(290 \mathrm{mAh} \mathrm{g}^{-1}\right)$ and $89 \%$ capacity retention under $500 \mathrm{~mA} \mathrm{~g}^{-1}$ after 1000 cycles $\left(212 \mathrm{mAh} \mathrm{g}^{-1}\right)$. Considering material sustainability and batteries' high performances, the colloidal electrolyte may provide a feasible substitute beyond the liquid and all-solid-state electrolyte of ZIBs.

KEYWORDS Zn-ion battery; Palygorskite; Inorganic; Colloidal electrolyte; Cycle stability

Jiawei Gao and Xuesong Xie contributed equally to this work

$\triangle$ Bingan Lu, luba2012@hnu.edu.cn; Jiang Zhou, zhou_jiang@csu.edu.cn

1 School of Materials Science and Engineering, Central South University, Changsha 410083, People's Republic of China

2 School of Physics and Electronics, Hunan University, Changsha 410082, People's Republic of China

3 Key Laboratory of Electronic Packaging and Advanced Functional Materials of Hunan Province, Central South University, Changsha 410083, People's Republic of China 


\section{Introduction}

The high energy density, low cost, and the environmentally friendly nature of aqueous zinc-ion batteries (ZIBs) are attractive especially for the large-scale stationary electrical energy storage [1, 2]. Unfortunately, ZIBs suffer from the growth of dendrite [3], element dissolution [4], and the formation of irreversible products [5]. In order to solve these issues, great efforts have been devoted to the study on the new Zn-host cathode discovery (manganese-based oxides [6], vanadium-based oxides [7, 8], prussian blue analogous [9], and other organic materials [2] etc.), mechanism exploration in oxide/non-oxide material, aqueous/ non-aqueous electrolyte [10, 11]. Moreover, much effort has been dedicated to the development of advanced metal Zn electrodes, from surface modification and structure designation (3D) to the alloy enhancement $[12,13]$. However, these methods can hardly meet all the requirements. As a result, the cycling life and Coulombic efficiency (CE) of ZIBs are still far behind the state-of-the-art lithium-ion batteries.

It is well known, as a vital component of the ZIBs, the electrolyte provides the basic operating environment to guarantee the long-standing stability and endurability of the battery [14-16]. A high-quality electrolyte could improve the performance of ZIBs. For example, Wang et al. [17] and Zhao et al. [18] recently reported that "water-in-salt" or "water-in-deep eutectic solvent" [19] high-concentration electrolyte could exhibit a nearly $100 \%$ $\mathrm{CE}$ and result in dendrite-free $\mathrm{Zn}$ plating/stripping during operation. This concept makes use of the fact that the nature of the coordination environment of the $\mathrm{Zn}^{2+}$ cation in the solution can be changed on a molecular level, leading a completely different electrochemistry [20]. However, under extreme concentration conditions, it is hard to apply in large-scale because of high-cost organic and salt precipitation issues at low temperatures [21]. Therefore, major stride should be taken in electrolyte exploration.

Here, we propose a new inorganic high-concentration colloidal electrolyte (HCCE) induced by the palygorskite nano-inorganic material to replace the normal liquid electrolyte in an aqueous ZIBs. The palygorskite has an intermediate structure between the chain structure and the lamellar structure, and it belongs to the 2:1 layer-chain microstructure, where the lattice displacement and good adsorption of zinc ions that are expected to reduce the much stronger and tight solvation sheath with water. Based on the HCCE, the energy barrier of de-solvation for hydrated $\mathrm{Zn}^{2+}$ at the surface is only $32.3 \mathrm{~kJ} \mathrm{~mol}^{-1}$, which is almost 1.7 times barrier less than that of routine liquid electrolyte $\left(52.5 \mathrm{~kJ} \mathrm{~mol}^{-1}\right)$, suggesting the high electrolyte-electrode kinetics enabled by HCCE. As a result, The HCCE not only has the same order of ionic conductivity as liquid electrolyte, but also has a higher $\mathrm{Zn}^{2+}$ transference number. The HCCE could promote simultaneously building of a protective layer on the surface of both anode and cathode, consequently suppress Mn dissolution and lead to a well-preserved and free-dendrite metal $\mathrm{Zn}$ anode. The battery with HCCE achieves high Coulombic efficiency and longer cycle life, exhibiting excellent durability up to 400 cycles at $200 \mathrm{~mA} \mathrm{~g}^{-1}$ with no capacity fading $\left(290 \mathrm{mAh} \mathrm{g}^{-1}\right)$ and maintaining a specific capacity of $212 \mathrm{mAh} \mathrm{g}^{-1}$ after 1000 cycles at $500 \mathrm{~mA} \mathrm{~g}^{-1}$. It can be concluded that the HCCE provides a comprehensive enhancement, and offer an available and affordable avenue for the highly efficient utilization of $\mathrm{Zn}$ in $\mathrm{Zn}$-based batteries.

\section{Experimental Section}

\subsection{Material Synthesis}

Preparation of $\alpha-\mathrm{MnO}_{2}$ : In a modified synthesis of $\alpha$ $\mathrm{MnO}_{2}$ [22], $0.00225 \mathrm{~mol} \mathrm{MnSO}_{4} \cdot \mathrm{H}_{2} \mathrm{O}$ was added to $15 \mathrm{~mL}$ deionized water and stirred it until a clear solution was obtained. Then, $15 \mathrm{~mL} 0.1 \mathrm{M} \mathrm{KMnO}_{4}$ aqueous solution was slowly added into the above solution. The mixture was stirred at room temperature for $1 \mathrm{~h}$. The solution was then transferred to a Teflon-lined autoclave and heated at $160{ }^{\circ} \mathrm{C}$ for $12 \mathrm{~h}$. After cooling down, the obtained material was collected by centrifugation, washed three times with deionized water, and dried in an air oven at $60{ }^{\circ} \mathrm{C}$.

Preparation of a high-concentration colloidal electrolyte: $2 \mathrm{M} \mathrm{ZnSO}_{4}+0.1 \mathrm{M} \mathrm{MnSO}_{4}$ was used as a liquid electrolyte. The high-concentration colloidal electrolyte (HCCE) was prepared by mixing palygorskite ( 800 mesh, Weifang Purun Trading Co. Ltd, China) and liquid electrolyte in a 
mass ratio of $3: 10(1: 10,2: 10$, and $4: 10)$ which signed $30 \%$ $(10 \%, 20 \%$, and $40 \%)$. Before using, we will mix the raw palygorskite with a large amount of deionized water to form slurry evenly, centrifuge it at 8000 RPM for $5 \mathrm{~min}$, and then remove the impurity. The HCCE (slurry) could be obtained by pouring palygorskite into the liquid electrolyte, mixing, stirring, and then under ultrasonic at least $60 \mathrm{~min}$ (it can be used after standing for $12 \mathrm{~h}$ without any other treatment).

\subsection{Material Characterization}

$\mathrm{X}$-ray diffraction (XRD) measurements were performed using a Rigaku D/max2500 powder diffractometer $(\mathrm{Cu}$ $\mathrm{K} \alpha, \lambda=0.15405 \mathrm{~nm}$ ). Determination of elements in solution by inductively coupled plasma optical emission spectrometry (ICP-OES). XPS spectra were performed on an ESCALAB 250Xi X-ray photoelectron spectrometer (Thermo Fisher) and C $1 \mathrm{~s}$ peak is $284.8 \mathrm{eV}$. SEM images were collected on a Nova Nano SEM 230 operating at $10 \mathrm{kV}$. The element analysis and morphology measurements were obtained by energy-dispersive X-ray (EDS) and transmission electron microscope (TEM, HEM2100F/UHR). FTIR was performed with a Nicolet 6700 spectrometer instrument. The surface morphology of $\mathrm{Zn}$ anode was observed by AFM (CSPM 5000).

(a)

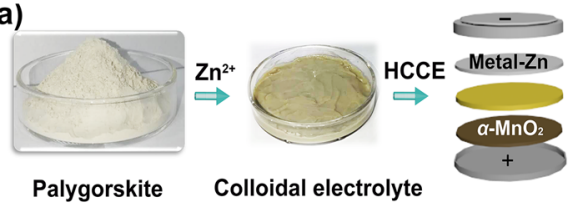

(b)

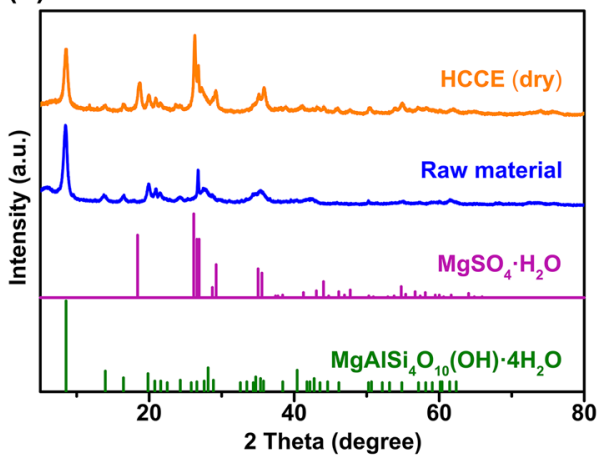

\subsection{Electrochemical Characterization}

The cathode electrodes were prepared by coating a slurry of $70 \% \alpha-\mathrm{MnO}_{2}, 20 \%$ acetylene black, and $10 \%$ polyvinylidene fluoride (PVDF) onto stainless steel wire mesh (SSWM) and then let it dry at $80{ }^{\circ} \mathrm{C}$ in vacuum overnight. $\mathrm{Zn} / \mathrm{MnO}_{2}$ batteries were assembled using a glass fiber filter as a separator (Whatman GF/A), HCCE as the electrolyte and Zn foil as the anode (the HCCE was coated on both sides of separator) in CR2016 coin cells. The charge/discharge experiments were carried out on the multichannel battery testing system (LAND CT2001A). The CV and EIS tests were recorded using an electrochemical workstation (CHI660C). Galvanostatic intermittence titration technique (GITT) was measured by the Arbin test system.

\section{Result and Discussion}

\subsection{Materials Synthesis and Characterization}

The inorganic colloidal electrolyte is prepared by directly added the normal liquid electrolyte $\left(2 \mathrm{M} \mathrm{ZnSO}_{4}+0.1 \mathrm{M}\right.$ $\mathrm{MnSO}_{4}$ ) to the raw palygorskite inorganic material, and the Tyndall effect is observed (Fig. S1). When the concentration of palygorskite is further increased, the white color material turns into yellow-brown and high viscosity (Figs. 1a and S2).
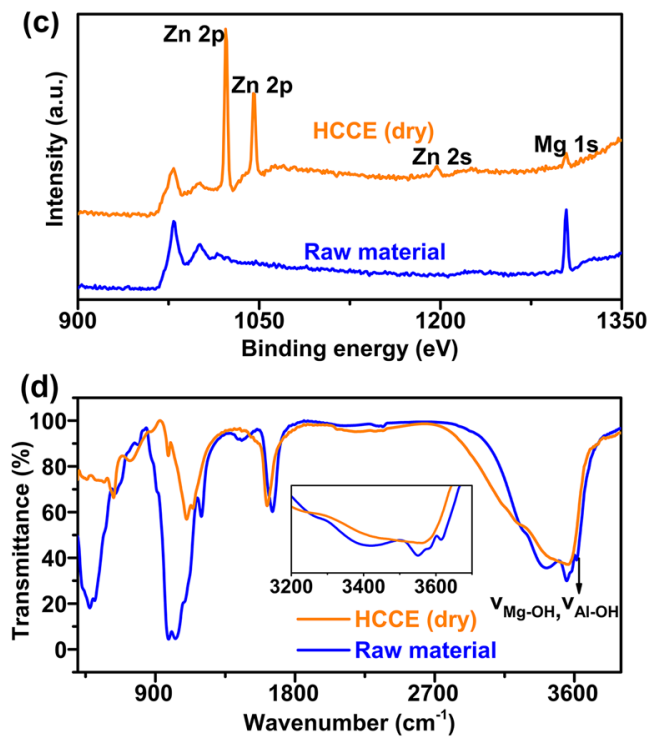

Fig. 1 a A simple process of colloidal electrolyte preparation and application. b XRD patterns of raw material (palygorskite) and colloidal electrolyte (after drying). c XPS full-spectrum image of raw material (palygorskite) and colloidal electrolyte (after drying). d FTIR spectra of raw material (palygorskite) and colloidal electrolyte (after drying) 
Compared with the raw stick materials (Fig. S3), the palygorskite that immerses into liquid electrolyte illustrate a uniform distribution of $\mathrm{Zn}$ element around the stick in energy-dispersive X-ray (EDX) elemental mapping analyses (Fig. S4), confirming that $\mathrm{Zn}^{2+}$ did react with the palygorskite via absorption or ions exchange [23]. As shown in Fig. 1b, the XRD pattern of HCCE remains a characterized palygorskite phase composition like raw materials (JCPDS\#29-0855), which confirmed the $\mathrm{Zn}$ or Mn ions did not change this phase structure merely by means of the isomorphic substitution reaction. While a new phase $\mathrm{MgSO}_{4} \cdot \mathrm{H}_{2} \mathrm{O}$ (JCPDS\#33-0882) appears in the colloidal electrolyte after drying, suggesting the replacement of lattice $\mathrm{Mg}$ by the $\mathrm{Zn}$ as the reported studies [23-25].

The XPS spectral characterization of the raw material (palygorskite) and the colloidal electrolyte is shown in Fig. 1c. For colloidal electrolyte powders, $\mathrm{Zn} 3 p$ double peak $(\sim 1022.89$ and $1045.97 \mathrm{eV})$ and $\mathrm{Zn} 2 s$ peak $(\sim 1197.16 \mathrm{eV})$ are both observed and the intensity of Mg $1 s$ peak $(\sim 1304.2 \mathrm{eV})$ is significantly reduced compared to that of raw ones, which proves that the large quantity of $\mathrm{Mg}$ in palygorskite is indeed replaced by Zn element. The Fourier transform infrared (FTIR) results show that the intensity of obvious absorption peak appearing at about $3615 \mathrm{~cm}^{-1}\left(\mathrm{v}_{(\mathrm{Mg}, \mathrm{Al})-\mathrm{OH}}\right)$ and $3585 \mathrm{~cm}^{-1}$ $\left(\mathrm{v}_{\mathrm{Mg}_{2}-\mathrm{OH}}\right)$ is largely reduced (Fig. 1d), which is well established in the literature as being because of $\mathrm{v}_{(\mathrm{Mg}, \mathrm{Al})-\mathrm{OH}}$ and $\mathrm{v}_{\mathrm{Mg}_{2}-\mathrm{OH}}$ stretching mode of raw materials $[26,27]$. This indicates that the strong interaction of $\mathrm{Mg}-\mathrm{OH}$ may be replaced by the $\mathrm{Zn}-\mathrm{OH}$ group. To conclude, the equation for the HCCE can be summarized as below $[28,29]$ :

$\mathrm{MgAlSi}_{4} \mathrm{O}_{10}(\mathrm{OH}) \cdot 4 \mathrm{H}_{2} \mathrm{O}+y \mathrm{Zn}^{2+}$

$\leftrightarrow \mathrm{Zn}_{y} \mathrm{Mg}_{1-y} \mathrm{AlSi}_{4} \mathrm{O}_{10}(\mathrm{OH}) \cdot 4 \mathrm{H}_{2} \mathrm{O}+y \mathrm{Mg}^{2+}$

Based on the analysis, it indicates that $\mathrm{Zn}^{2+}$ strongly interacts with the palygorskite, enabling $\mathrm{Zn}^{2+}$ insertion among internal crystals (isomorphic substitution reaction), the $\mathrm{Zn}^{2+}$ is not exposed to the environment surrounded by solvent molecules $\left(\mathrm{H}_{2} \mathrm{O}\right)$ for a long time. Next, the effect of the HCCE based on the limited liquid water on the electrode and battery performance will be analyzed.

\subsection{Electrochemical Performance of $\mathrm{Zn} / \mathrm{MnO}_{2}$ Cells Cycled with HCCE}

The cyclic voltammetry curves of HCCE showed it owns $0.83 \mathrm{~mA} \mathrm{mg}^{-1}$ peak current at charge state and $0.33 \mathrm{~m}$
A mg ${ }^{-1}, 0.31 \mathrm{~mA} \mathrm{mg}^{-1}$ peak current at discharge state which is higher than that of liquid with $0.76 \mathrm{~mA} \mathrm{mg}^{-1}$ charge peak current, 0.25 and $0.19 \mathrm{~mA} \mathrm{mg}^{-1}$ discharge peak current at the scan of $0.1 \mathrm{mV} \mathrm{s}^{-1}$, which means that HCCE has the higher electrochemical reactivity and specific capacity than liquid as shown in Fig. 2a. As displayed in Fig. S5b, the cell with HCEE possesses considerably higher capacities than that of the cell with a liquid electrolyte at each rate in the voltage range of $0.8-1.8 \mathrm{~V}$ (vs. $\mathrm{Zn}^{2+} / \mathrm{Zn}$ ). Figure $2 \mathrm{~b}$ shows the charge/ discharge curves of the cell with HCCE cycled at a current rate of $200 \mathrm{~mA} \mathrm{~g}^{-1}$. After the first cycle of activation, the cell with HCCE maintains stable capacities of around $290 \mathrm{mAh} \mathrm{g}^{-1}$ with a high $\mathrm{CE}$ of around $100 \%$ and well stable voltage-platform as well as high capacity retention (almost $100 \%$ after 400 cycles) under the low current density as shown in Fig. 2c (the comparison of circulating performance electrolyte with different palygorskite concentration is shown in Fig. S6). Even at high $1000 \mathrm{~mA} \mathrm{~g}^{-1}$ current density, the cell cycled with HCCE delivers a nearly $100 \%$ capacity retention after 200 cycles with a specific capacity of $202 \mathrm{mAh} \mathrm{g}^{-1}$ as shown in Fig. 2d. For the long-standing performance, the cell equipped with HCCE possessed superior durability over 1000 cycles at $500 \mathrm{~mA} \mathrm{~g}^{-1}$ (Fig. 2f) than that of the liquid electrolyte with same conditions. Specifically, the last ten charge/discharge curves of the cell at 1000 still remain the high operating voltage (about 1.35 V, see Fig. S7), further demonstrating the high stability and reversibility of the cell with HCCE, Accordingly, Fig. 2e shows the comparison of cycle number and capacity retention based on different electrolytes in mangan-based materials (mainly manganese dioxide) in recent years, the cell cycled with HCCE shows the superior electrochemical performance compared to others.

The EIS data of the $\mathrm{Zn} / \mathrm{MnO}_{2}$ battery (Fig. S5c), fitted by the equivalent circuit shown in the inset of Fig. S5c, shows a decrease of charge transfer resistance with the increase of concentration of colloidal, which suggests the good conductivity and high electrolyte-electrode kinetics enabled by HCCE. Table S1 presents an ohmic internal resistance $\left(R_{\mathrm{s}}\right.$, Liquid, $3.2 \Omega ; R_{\mathrm{S}}$, Colloidal, $\left.2.1 \Omega\right)$ and a charge transfer resistance $\left(R_{\mathrm{ct}}\right.$, Liquid, $1694 \Omega ; R_{\mathrm{ct}}$, Colloidal, $297 \Omega$ ), respectively. Besides, the HCCE can effectively suppress the self-discharge phenomenon (Fig. $\mathrm{S} 5 \mathrm{~d})$. The one of main contributions to the self-discharge 
(a)

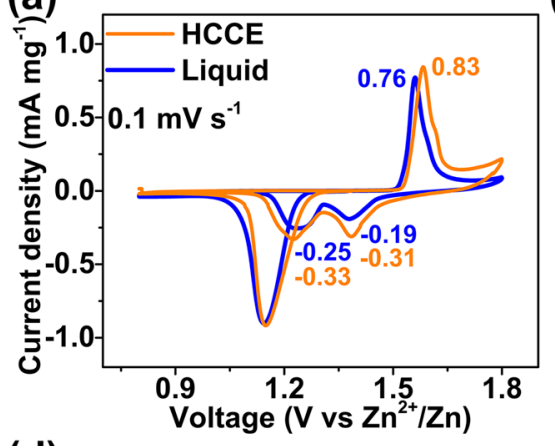

(d)

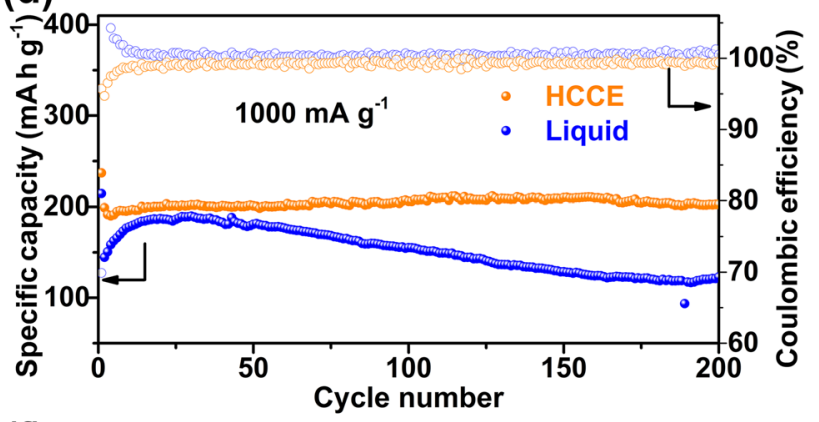

(b)

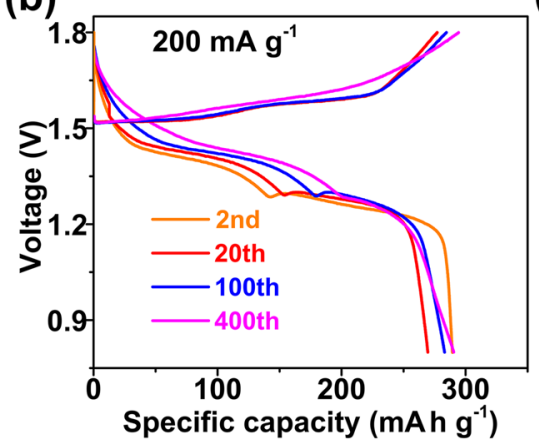

(c)

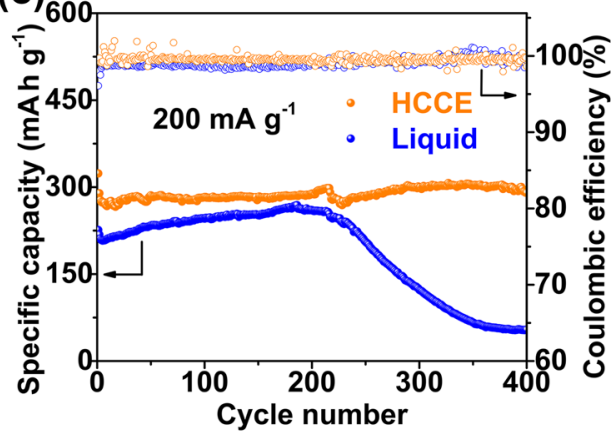

(e)
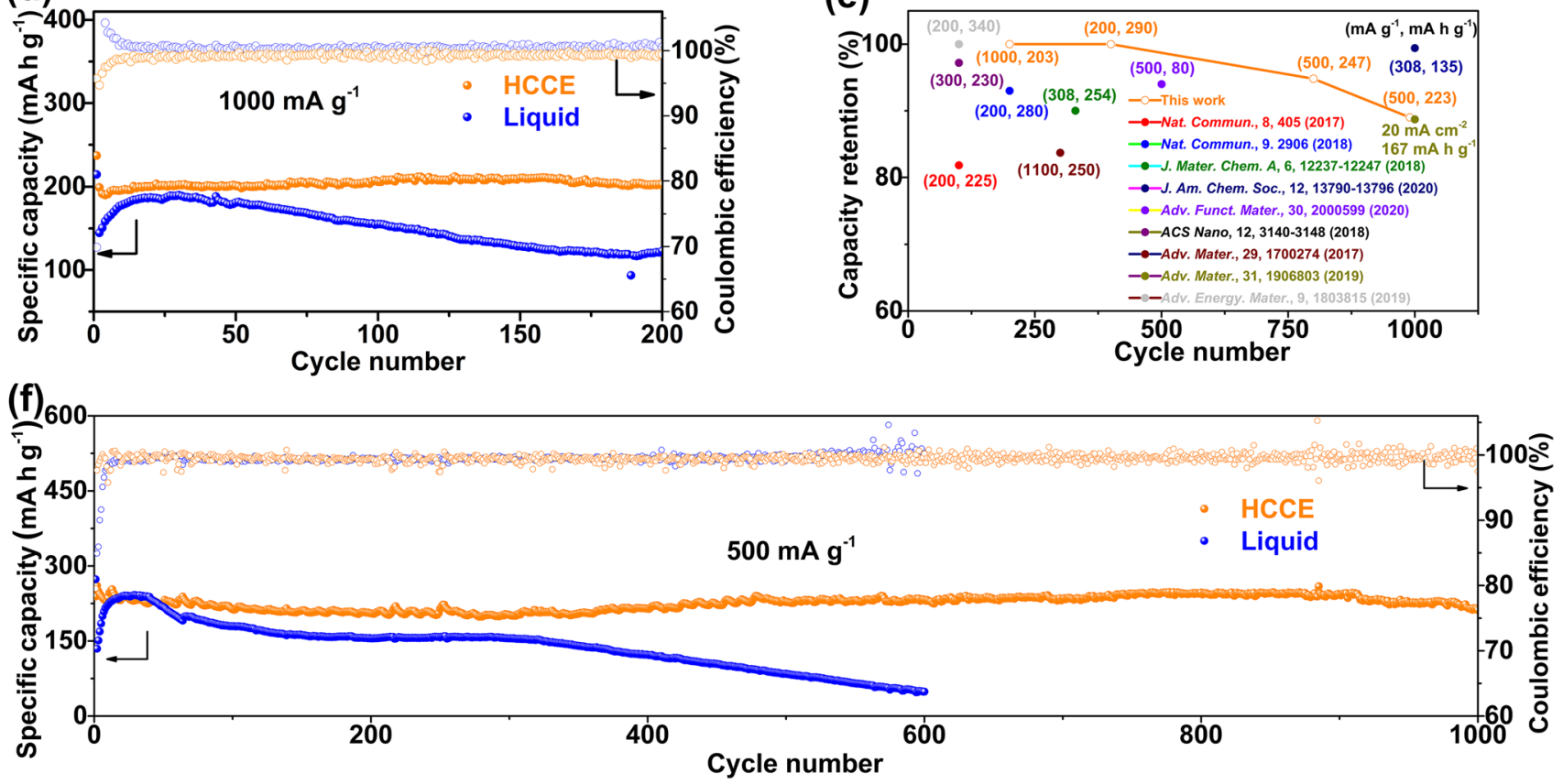

Fig. 2 a CV curves (the first cycle) at a scan rate of $0.1 \mathrm{mV} \mathrm{s}^{-1}$ with the HCCE and liquid electrolyte. b Charge-discharge curves under different cycles with the HCCE at $200 \mathrm{~mA} \mathrm{~g}^{-1}$. c Cycling performance of the cell with HCCE and liquid electrolyte cells at $200 \mathrm{~mA} \mathrm{~g}^{-1}$. $\mathbf{d ~ C y c l i n g}$ performance of the cell with HCCE and liquid electrolyte cells at $1000 \mathrm{~mA} \mathrm{~g}^{-1}$. e Capacity retention versus cycle number for electrolyte reported in aqueous $\mathrm{Zn}$ /mangan-based materials (mainly manganese dioxide) batteries, note: the current density and final specific capacity are indicated in the figure. $\mathbf{f}$ Long-life cycling performance of the cell with HCCE and liquid electrolyte at $500 \mathrm{~mA} \mathrm{~g}^{-1}$

is the faradaic reaction, which includes the decomposition of the electrolyte and the redox side reactions caused by impurities or functional groups on the electrode surface [30-32]. This indicates that the HCCE is capable of inhibiting side reactions during the practical application. In order to figure out the mechanism of performance enhancement for HCCE, the characterizations were conducted on the electrodes and electrolyte in the following part.

\subsection{Analysis of Cathode of $\mathrm{Zn} / \mathrm{MnO}_{2}$ Battery}

The $\mathrm{MnO}_{2}$ is of interest due to its low cost, moderate discharge potential, and acceptable rate/cycle performance, as well as its high theoretical capacity of about $308 \mathrm{mAh} \mathrm{g}^{-1}$ $\left(\mathrm{Zn}_{0.5} \mathrm{MnO}_{2}\right)$. However, It is well known that the dissolution of $\mathrm{Mn}$ is a major issue for Mn-based electrodes due to Jahn-Teller effect $[33,34]$, leading to capacity fading and short cycle life [35]. To analyze the superior performance, the 
inductively coupled plasma optical emission spectrometry (ICP-OES) was conducted to evaluate Mn concentration in $\mathrm{Zn} / \mathrm{MnO}_{2}$ battery during cycling. It shows that the dissolution of the Mn element could be effectively alleviated by the colloidal electrolyte (with $2 \mathrm{M} \mathrm{ZnSO}_{4}$ in the absence of $\mathrm{MnSO}_{4}$ ) at each cycle (Fig. 3a). For the postmortem electrode a wellpreserved cathode morphology is achieved after discharging to $1.0 \mathrm{~V}$ at $200 \mathrm{~mA} \mathrm{~g}^{-1}$ (Fig. 3b), 200 cycles at $1 \mathrm{~A} \mathrm{~g}^{-1}$ (Fig. S8), and 400 cycles at $0.2 \mathrm{~A} \mathrm{~g}^{-1}$ (Fig. S9), respectively, whereas the liquid one delivers a clearly dissolved feature compared to HCCE (Fig. 3c), which may be caused by the severe Mn dissolution and exacerbated by the acute acid due to local $\mathrm{pH}$ fluctuation as the previous study reported [36]. To further analyze, the ex-situ Transmission electron microscopy (TEM) test of cathode discharged to $0.8 \mathrm{~V}$ after being cycled with HCCE and liquid was performed. It was found that the diameter of $\mathrm{MnO}_{2}$ nanorod after being cycled with liquid was only $8.1 \mathrm{~nm}$ (Fig. S10), whereas the HCCE one (a)

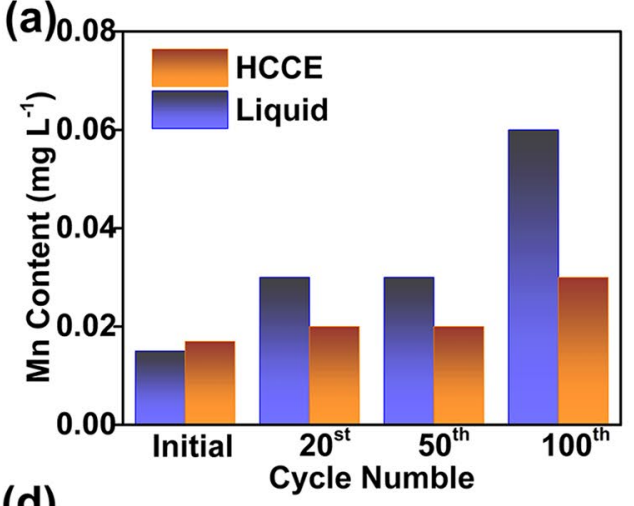

(d)

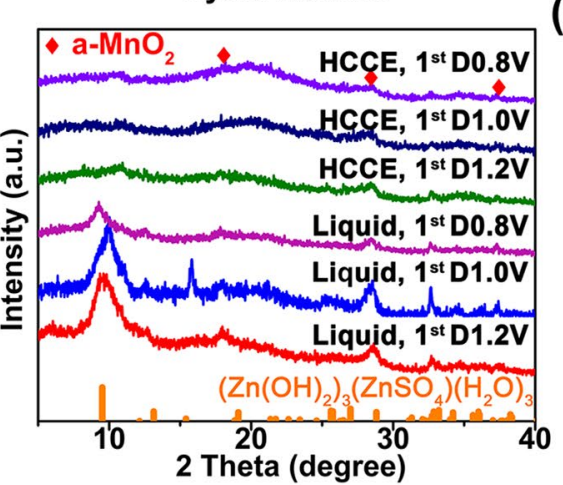

(g)

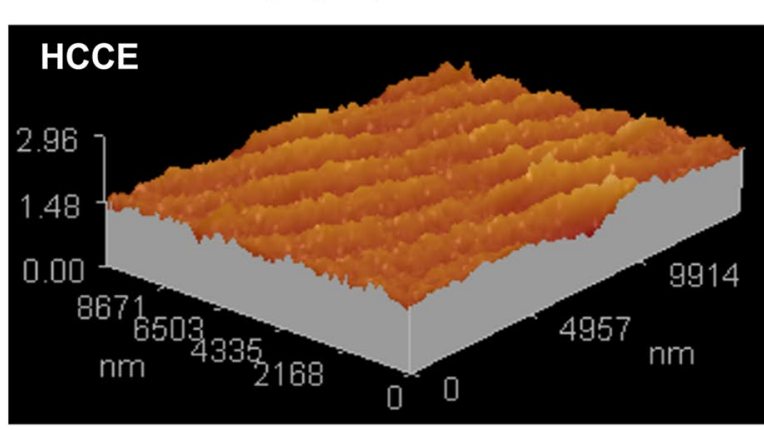

(b)

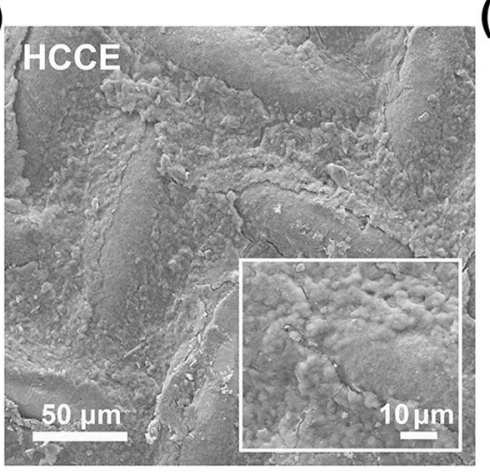

(e)

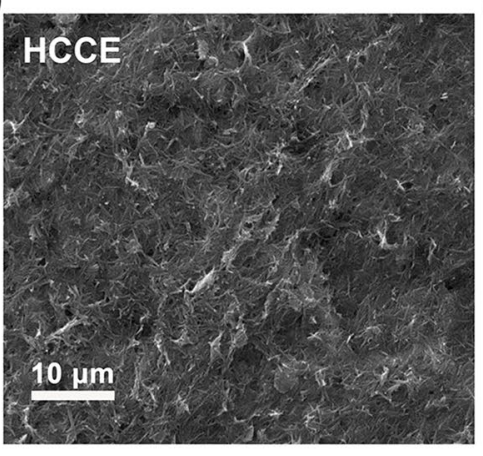

(c)

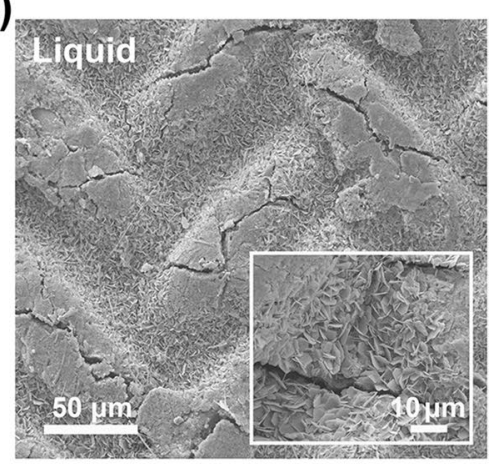

(f)

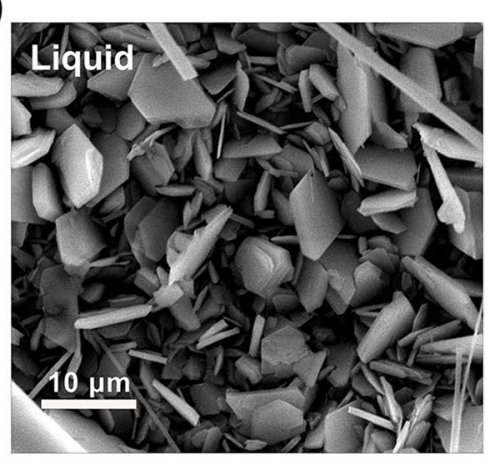

(h)

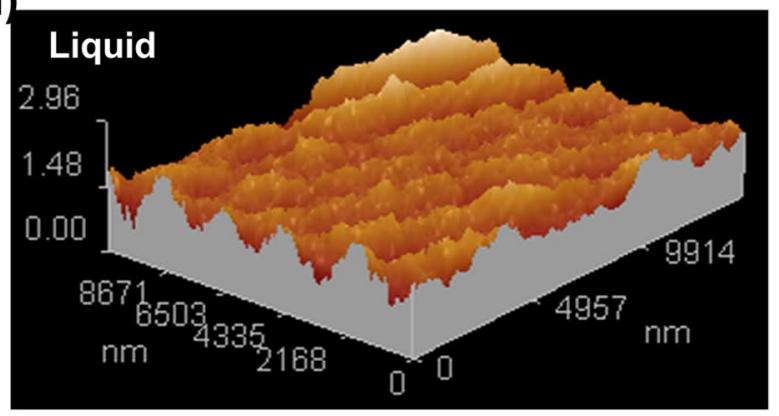

Fig. 3 a Element analysis of dissolved $\mathrm{Mn}^{2+}$ in $\mathrm{Zn} / \mathrm{MnO}_{2}$ battery during cycling with $2 \mathrm{M} \mathrm{ZnSO}_{4}$ aqueous electrolyte and colloidal electrolyte ( $2 \mathrm{M} \mathrm{ZnSO}_{4}+$ palygorskite). SEM images of $\mathbf{b}$ cathode of the battery with HCCE and $\mathbf{c}$ the battery with liquid electrolyte after initial fully discharge to $1.0 \mathrm{~V}$ at $200 \mathrm{~mA} \mathrm{~g}^{-1}$. d ex-situ XRD patterns of the cell with $\mathrm{HCCE}$ and liquid electrolyte discharged/charged to different voltage states at $200 \mathrm{~mA} \mathrm{~g}^{-1}$. SEM images of $\mathbf{e}$ anode of the battery with HCCE and $\mathbf{f}$ the battery with liquid electrolyte cycled for 200 cycles $1000 \mathrm{~mA} \mathrm{~g}^{-1}$. AFM images of $\mathbf{g}$ anode of the battery with $\mathrm{HCCE}$ and $\mathbf{h}$ the battery with liquid electrolyte cycled for $200 \mathrm{cycles} 1000 \mathrm{~mA} \mathrm{~g}^{-1}$ 
keeps around $43 \mathrm{~nm}$ and is surrounded by a layer of membrane (the fiber shapes) as result of the continuous $\mathrm{Mg}$ and Zn but not Mn elements in EDX analyses (Fig. S11).

Apart from the Mn dissolution, the key point is to illuminate the mechanism of $\mathrm{MnO}_{2}$-based $\mathrm{Zn}$ ions battery. ExXRD characterization was carried out to trace the phase changes of the cathode during the charge-discharge process. A sharp peak at around $10^{\circ}$ ( 2 thetas) is indexed to $\mathrm{ZnSO}_{4} \cdot 3 \mathrm{Zn}(\mathrm{OH})_{2} \cdot n \mathrm{H}_{2} \mathrm{O}(n=3$ with JCPDS No. $78-0247)$ (Fig. 3d), which illustrates the formation of massive basic zinc sulfate at the surface of $\mathrm{MnO}_{2}$ cathode in the liquid electrolyte at discharge states of $1.2,1.0$, and $0.8 \mathrm{~V}$, respectively. On the contrary, no obvious new peaks are observed at around $10^{\circ}$ for the same state of discharge in the HCCE system, which means less by-products formation at the discharge/charge states $[33,37]$. which is confirmed by the clean surface morphology of SEM images based on HCCE under corresponding voltage (discharge state of 1.0 and $0.8 \mathrm{~V}$, Figs. $3 \mathrm{~b}, \mathrm{c}$ and S12). To be summarized, the superior performance of $\mathrm{Zn} / \mathrm{MnO}_{2}$ battery based on HCCE as the formation of a protective layer surrounding $\mathrm{MnO}_{2}$ materials, which is mainly caused by the suppression of Mn dissolution and irreversible basic zinc sulfate.

Also, the $\mathrm{Zn}^{2+}$ ion diffusion coefficients was in-depth analyzed by galvanostatic intermittent titration technique (GITT) technology and CV experiment. It confirmed that the cell with HCCE and the liquid ones exhibited similar electrochemical reaction kinetics, e.g., $\mathrm{Zn}^{2+}$ ion diffusion coefficients (Fig. S13), capacitive contribution (Fig. S15) and ionic conductivity (HCCE: $1.1 \times 10^{-2} \mathrm{~S} \mathrm{~cm}^{-2}$, liquid: $0.92 \times 10^{-2} \mathrm{~S} \mathrm{~cm}^{-2}$ ) (Fig. S16). This means that $\mathrm{Zn}^{2+}$ can pass through the film easily without obstruction. Next, the influence of HCCE on the anode will be discussed.

\subsection{Analysis of Anode of $\mathrm{Zn} / \mathrm{MnO}_{2}$ Battery}

The plating/stripping stability of Zn cycled with HCCE was undertaken by the galvanostatic measurements in $\mathrm{Zn} / \mathrm{Zn}$ symmetrical battery at the three different current densities $\left(0.28,1.13\right.$, and $2.83 \mathrm{~mA} \mathrm{~cm}^{-2}$, respectively) as shown in Fig. S17a. The HCCE battery has smaller voltage fluctuations without obvious polarization in comparison with the liquid one. Long-time plating/stripping stability of the $\mathrm{Zn} / \mathrm{Zn}$ battery is confirmed by the stable voltage-time curves with $29.8 \mathrm{mV}$ voltage hysteresis at the end of $400 \mathrm{~h}$ (Fig. S17b). The stability may deduce the facility of charge transference as shown in Fig. S17c. Besides, the plating/stripping reversibility of $\mathrm{Zn}$ in the HCCE was investigated by using cyclic voltammetry (CV) measurement for $\mathrm{Zn}-\mathrm{Zn}$ symmetrical battery. As shown in Fig. S18, the cell with HCCE shows better reversibility of $99 \%$ (cathodic) than that of liquid one $(65 \%)$ at a scan rate of $2 \mathrm{mV} \mathrm{s}^{-1}$, which is similar to that of the high-concentration $1 \mathrm{~m} \mathrm{Zn}(\mathrm{TFSI})_{2}+20 \mathrm{~m}$ LiTFSI-based electrolytes [17].

In order to get further insight into the interfacial charge transfer process, the activation energies $\left(E_{a}\right)$ representing the journey of $\mathrm{Zn}^{2+}$ were obtained through fitting the semicircles $\left(R_{s}, R_{\mathrm{ct}}\right)$ in $\mathrm{Zn}-\mathrm{Zn}$ symmetrical batteries (Fig. S19a, b) at different temperatures from 0 to $40{ }^{\circ} \mathrm{C}$ and the $E_{a}$ were related to the environment, temperature, etc. This is becasue Abe and co-workers have confirmed that the transport of Li through the SEI and charge transfer showed a close dependence on temperature $[38,42] . E_{\mathrm{a} 1}$ represents the transport process of $\mathrm{Li}^{+} . E_{\mathrm{a} 2}$ exhibits the de-solvation energy of $\mathrm{Li}^{+}$that has been widely accepted as the dominant barrier in the electrochemical process [39, 40]. The dissolution of zinc ions at the anode interface is restricted by the structure of the solvated sheath and the double electric layer, the interfacial charge transfer behavior is highly similar to that of lithium ion [41,42]. The $E_{a 1}$ and $E_{a 2}$ values are tested under the same conditions, both of $E_{a l}$ and $E_{a 2}$ are in line with the law of Arrhenius: $\frac{1}{R_{\mathrm{ct}}}=A \exp \left(-E_{a} / \mathrm{RT}\right)$. As a result of the calculation (Fig. $\mathrm{S} 19 \mathrm{c}, \mathrm{d}$ ), $E_{a 1}$ is $4.5 \mathrm{~kJ} \mathrm{~mol}^{-1}$ and $E_{a 2}$ is $32.3 \mathrm{~kJ} \mathrm{~mol}^{-1}$ in the HCCE, smaller than that of liquid electrolyte $\left(E_{a 1}\right.$ is $10.7 \mathrm{~kJ} \mathrm{~mol}^{-1}$ and $E_{a 2}$ is $52.5 \mathrm{~kJ} \mathrm{~mol}^{-1}$ ). Compared with liquid electrolytes, the smaller charge transfer activation energy exhibits the easier transfer of solvated zinc ion between the $\mathrm{Zn}$ anode and the HCCE interface, which is consistent with EIS results for Zn-Zn symmetric batteries (Fig. S17c). Besides, as for the reveal of high ions conductivity, the distribution of pore diameter for the HCCE (dry) is mainly concentrated on $3.6 \mathrm{~nm}$ range and no other large holes (Fig. S20), which may lead to the conducive channel to confine $\mathrm{Zn}^{2+}$ diffusion and the massive charge transference. So as to avoid dendrite growth caused by excessive $\mathrm{Zn}^{2+}$ accumulate on local at the zinc anode surface with available charge transference capacity. Therefore, it can be confirmed by the SEM results that the $\mathrm{Zn}$ anode maintained a relatively flat and smooth surface without obvious 
dendrite (or accumulation) in the presence of the HCCE after 200 cycles at $1000 \mathrm{~mA} \mathrm{~g}^{-1}$ (Fig. 3e), while rough aggregation and lots of remainings with hexagon layer structure were observed for liquid ones (Figs. $3 \mathrm{f}$ and S21a), which are further confirmed by the more uniform surface atomic force microscope (AFM) in HCCE system as shown in Fig. 3g. As for the hexagon layer structure, many researchers blame it on the partially irreversible $\mathrm{Zn}$ based layered double hydroxides ( $\mathrm{Zn}$ LDHs), which is easy to detach from the electrode surface [43, 44]. Large amounts of $\mathrm{Zn} \mathrm{LDHs}$ are randomly distributed and accumulated on the surface of zinc anode cycled with liquid (Figs. 3f and S21a), which makes the surface uneven (Fig. 3h). However, no Zn LDHs products appeared on the $\mathrm{Zn}$ anode cycled with HCCE (Figs. 3e and S21b, c), and the surface remained smooth (Fig. 3g). Along with concomitant precipitation of a $\mathrm{Zn} \mathrm{LDH}$, the electrochemically insert by-products will passivate the electrode surface. In our system, Fig. S22 reveals the XRD pattern of the corresponding $\mathrm{Zn}$ anode after 200 cycles. For the HCCE system, no obvious new peaks are observed at around $11^{\circ}$ well-indexed to the zinc sulfate hydroxide hydrate of $6 \mathrm{Zn}(\mathrm{OH})_{2} \cdot \mathrm{ZnSO}_{4} \cdot 4 \mathrm{H}_{2} \mathrm{O}$ (JCPDS No. 11-0280), suggesting the side-reaction can be largely suppressed by HCCE. Besides the limited amount of free water, the battery cycled with HCCE showed two distinct half-circles (Fig. $\mathrm{S} 17 \mathrm{c})$, indicating the presence of interfacial impedance, confirming that the HCCE coated the electrode to form a protective layer. Therefore, the introduction of HCCE not only avoids the direct contact between metal $\mathrm{Zn}$ and free $\mathrm{H}_{2} \mathrm{O}$ by the formation of protective layer with good ions conductivity to reduce the irreversible products along with $\mathrm{Zn}^{2+}$ plating/stripping process on the anode surface, but also decreases the de-solvation barrier, facilitating the charge transfer of $\mathrm{Zn}^{2+}$.

On the other hand, corrosion of $\mathrm{Zn}$ anode and deposition model has also carried out for HCCE group compared to liquid one, respectively. The $\mathrm{Zn}$ corrosion was analyzed by a linear polarization test. Compared with the liquid electrolyte, the HCCE had a lower corrosion current (Fig. S23a), illustrating the lower corrosion rate [45]. The variation in current-time curves at a constant potential can sensitively reflect the nucleation process and surface change [46, 47]. For the HCCE group, Fig. S23c shows that it only takes $40 \mathrm{~s}$ to reach current equilibrium for Chronoamperometry (CA) result, and remains almost constant with lower current density $\left(13.66 \mathrm{~mA} \mathrm{~cm}^{-2}\right)$ than that of liquid one $\left(24.75 \mathrm{~mA} \mathrm{~cm}^{-2}\right.$ ) at $200 \mathrm{mV}$ for $300 \mathrm{~s}$ that applied, which leads to much smooth surface morphology cycled with HCCE [45, 48]. Generally, to minimize the surface energy and the exposed area, $\mathrm{Zn}^{2+}$ ions tend to aggregate and grow into dendrites. The nucleation overpotential of $\mathrm{Zn} / \mathrm{Cu}$ cells cycled with HCCE is only $43 \mathrm{mV}$ (Fig. S23d), which increases the nucleation active sites of $\mathrm{Zn}^{2+}$ ions and the nucleation positions.

\subsection{Mechanism Analysis of Aqueous $\mathrm{Zn} / \mathrm{MnO}_{2}$ Battery with Colloidal Electrolyte}

Discussed above, the schematic diagram of interface protection effect in HCCE and liquid electrolyte as shown in Fig. 4a. The HCCE can form the protective layer to protect both cathode and anode of aqueous $\mathrm{Zn}$-ion battery. The protective layer can effectively inhibit the formation of irreversible electrode surface hydroxyl zinc sulfate, and it will not hinder the zinc ions transport compared with liquid. More importantly, it not only can inhibit the dissolution of manganese and corrosion of anode, lower de-solvation energy, and more nucleating active site can also maintain the $\mathrm{Zn}^{2+}$ continues for a long-time high reversible deposition/stripping reaction, to obtain the well-preserved electrode.

For the HCCE, Fig. 4c shows the FTIR spectra of colloidal electrolyte with various concentrations. As the concentration of palygorskite increases, the peak at about $1630 \mathrm{~cm}^{-1}$ $\left(\delta_{\mathrm{H}_{2} \mathrm{O}}\right)$ decreases, while the peak at about $3419 \mathrm{~cm}^{-1}\left(\mathrm{v}_{\mathrm{H}_{2} \mathrm{O}}\right)$ decreases with hypsochromic shift (HCCE: $3449 \mathrm{~cm}^{-1}$ $\left(v_{\mathrm{H}_{2} \mathrm{O}}\right)$, liquid: $\left.3419 \mathrm{~cm}^{-1}\left(\mathrm{v}_{\mathrm{H}_{2} \mathrm{O}}\right)\right)$. Attributing it to the polarsilica-hydroxyl of palygorskite forms hydrogen bonds with water molecules in the HCCE, which exerts a polar effect on water molecules and strengthens hydrogen bonds, resulting in peak $\left(\mathrm{v}_{\mathrm{H}_{2} \mathrm{O}}\right)$ blueshift. A large amount of free water is converted into adsorbed water of palygorskite [49], which slow the decomposition of free water in the electrolyte (similar to the high-concentration $1 \mathrm{M} \mathrm{Zn(TFSI)})_{2}+20 \mathrm{M}$ LiTFSIbased electrolytes [17]) making the decomposition voltage of HCCE $(1.60 \mathrm{~V})$ higher than that of liquid $(1.56 \mathrm{~V})$ (Fig. $\mathrm{S} 23 \mathrm{~b})$. In Fig. 4e, as the concentration increases, the Raman band $\left(\sim 240 \mathrm{~cm}^{-1}\right)$ is attributed to $\left[\mathrm{Zn}^{2+} \cdot \mathrm{OSO}_{3}{ }^{2-}\right]$ ligand mode [50]. Amplification peaks of $\left[\mathrm{Zn}^{2+} \cdot \mathrm{OSO}_{3}{ }^{2-}\right]$ ligand mode means a more constrict complex ion, which seem impossible in $\mathrm{ZnSO}_{4}$ solutions because limited solubility. 


\section{(a)}

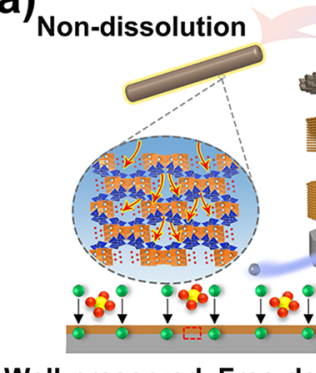

Well-preserved, Free-dendrite

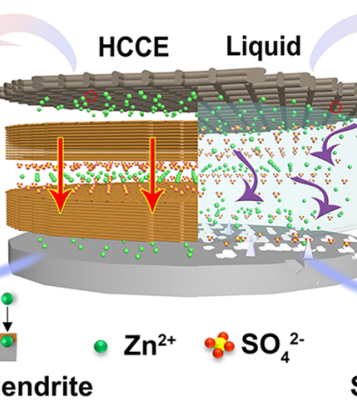

Side reactions, Dendrite

(b)
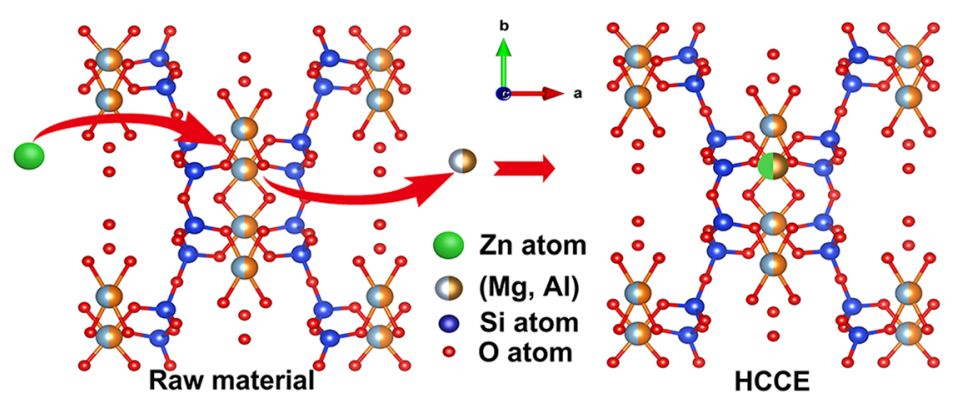

(c)

(d)
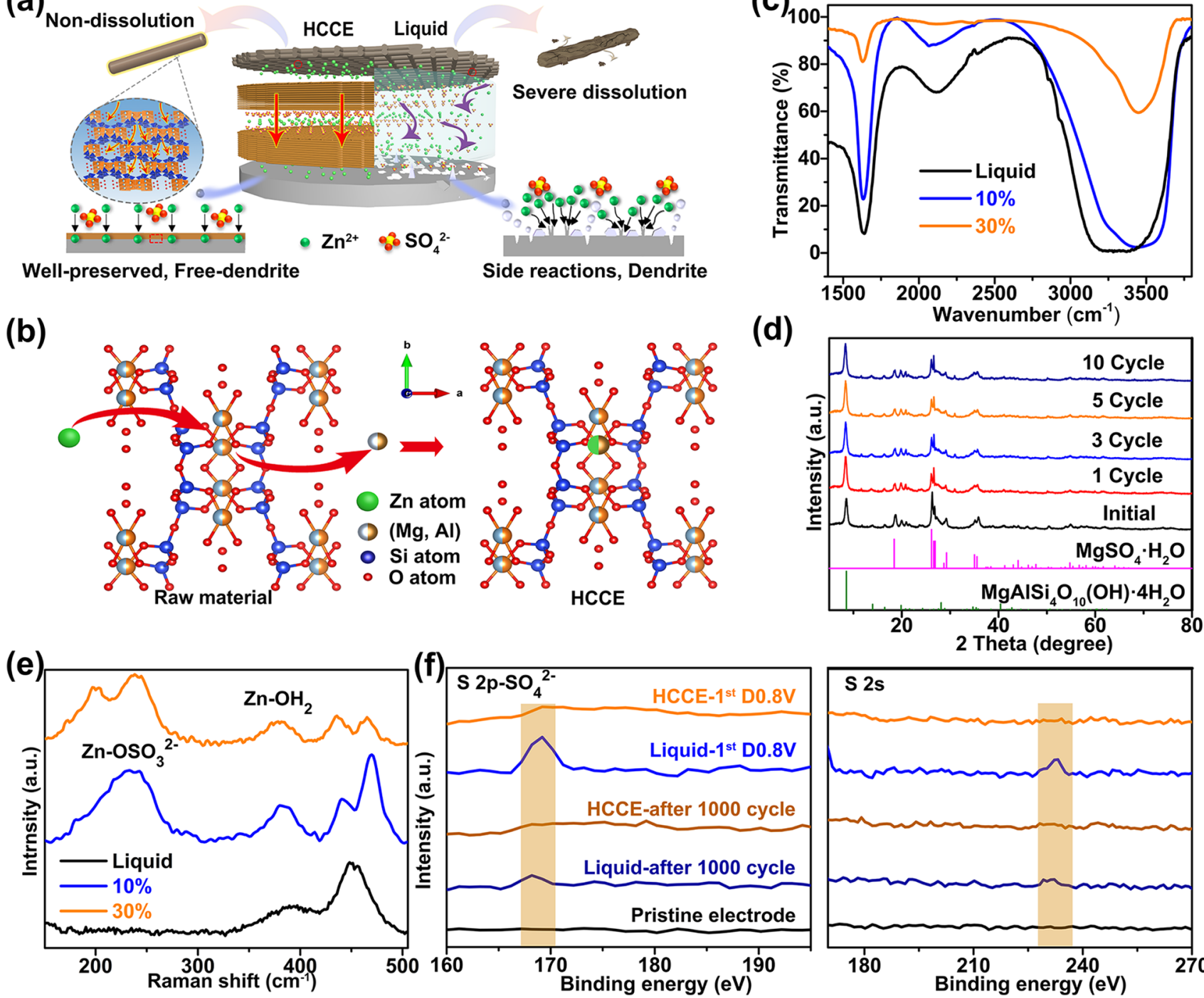

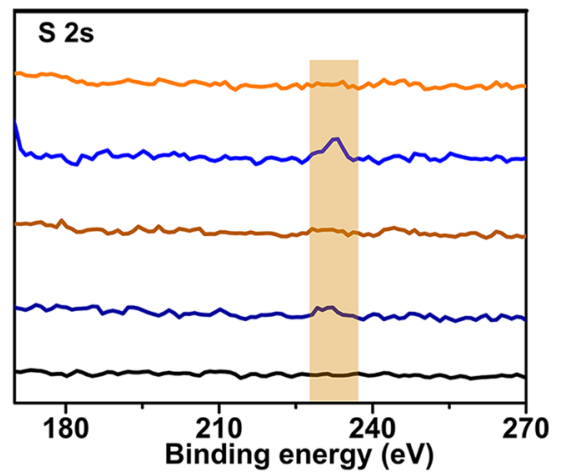

Fig. 4 a Schematic diagram of interface protection effect in HCCE and liquid electrolyte. b Ion exchange diagrams in the HCCE. c FTIR spectra $\left(1400-3800 \mathrm{~cm}^{-1}\right)$ of colloidal electrolyte with different concentration and liquid electrolyte. d XRD patterns of HCCE (after drying) with different cycles: initial (no cycle), 1 cycle, 3 cycles, 5 cycles, 10 cycles. e Raman spectra of colloidal electrolyte and liquid electrolyte. f XPS spectrum image of the cathode of the battery with HCCE and liquid electrolyte after initial discharge and 1000 cycles

Raman spectroscopy confirmed that palygorskite can remove a large number of water molecules to achieve the effect of super-saturated electrolyte and limit the solvation of $\mathrm{Zn}^{2+}$.

In order to further explore the way of $\mathrm{Zn}^{2+}$ passing through the HCCE, we speculate that palygorskite will spontaneously inhale and release $\mathrm{Zn}^{2+}$ according to the concentration gradient in the electrolyte. The HCCE (wash) is obtained by mixing HCCE with distilled water (dilute the $\mathrm{Zn}^{2+}$ concentration), centrifugation, and drying. The corresponding XRD (Fig. S24a) displays that the phase of $\mathrm{MgSO}_{4} \cdot \mathrm{H}_{2} \mathrm{O}$ disappears, and then returns to the pristine phase of the raw palygorskite. And after 3, 5, and 10 cycles, the XRD peaks of HCCE (Fig. 4d) almost same with initial (no cycle) which shows that the HCCE has good stability. As shown in the infrared spectrum at $\sim 3585 \mathrm{~cm}^{-1}\left(\mathrm{v}_{\mathrm{Mg}_{2}-\mathrm{OH}}\right)$ and $\sim 3615 \mathrm{~cm}^{-1}\left(\mathrm{v}_{(\mathrm{Mg}, \mathrm{Al})-\mathrm{OH}}\right)$ (Figs. $1 \mathrm{~b}$ and $\left.\mathrm{S} 24 \mathrm{~b}\right)$, the $\left(\mathrm{v}_{\mathrm{Mg}_{2}-\mathrm{OH}}\right)$ and $\left(\mathrm{v}_{(\mathrm{Mg}, \mathrm{Al})-\mathrm{OH}}\right)$ peak appears again. These results demonstrate that with the change of the concentration of zinc ions in the solvent, in order to bring the concentration of zinc ions in palygorskite and zinc ions in the solvent into a new dynamic equilibrium, the zinc ions and magnesium ions in palygorskite will spontaneously exchange with the zinc ions 
and magnesium ions in the solvent (Fig. 4b). Eventually, palygorskite will be spontaneously inhaled and release $\mathrm{Zn}^{2+}$ according to the concentration gradient in the electrolyte.

The XPS tests were carried out on the cathode cycled with HCCE and the liquid electrolyte after the first discharge state of $0.8 \mathrm{~V}$ and 1000 cycles, respectively. As shown in Fig. 4f (the full spectrum is shown in Fig. S25), two distinct peaks at 168.5 and $230 \mathrm{eV}$, representing the aggregation of $\mathrm{SO}_{4}{ }^{2-}$, are obviously observed in the electrode cycled with liquid electrolytes for both initial discharge and 1000 cycles, whereas the HCCE is absent of these signals. It suggests that the HCCE is capable of inhibiting the accumulation of anions on the surface, which may be due to the relatively higher intrinsic negative charges of palygorskite, the $\mathrm{SO}_{4}{ }^{2-}$ anions were repulsed away from surfaces $[49,51]$, further explaining why the electrode surface can inhibit the formation of zin hydroxy sulfate. Meanwhile, the higher $\mathrm{Zn}^{2+}$ transference number of the HCCE $\left(\mathrm{t}_{\mathrm{Zn}}{ }^{2+} \sim 0.64\right.$ compared to $\sim 0.50$ for liquid ones) (Fig. S26) based on the same ionic conductivity between HCCE and liquid. It indicates that more $\mathrm{Zn}^{2+}$ ions are involved in effective migration in the HCCE, which is attributed to the limited migration of anions $\left(\mathrm{SO}_{4}{ }^{2-}\right)$ [52]. In this way, the presence of $\mathrm{Zn}^{2+}$ ions within the palygorskite is protected, and the solvation effect can be reduced. Based on the lower de-solvation energy of the HCCE, $\mathrm{Zn}^{2+}$ ions can pass through this "protective layer" quickly and making it easier for $\mathrm{Zn}^{2+}$ ions to deposit near the initial adsorption of the $\mathrm{Zn}$ anode, thus significantly inhibiting the formation of irreversible product (such as basic zinc sulfate) and dendrite growth.

\section{Conclusion}

In summary, the HCCE can form the protective layer to protect both the cathode and anode of an aqueous $\mathrm{Zn}$-ion battery. For the cathode, the presence of the protective film can inhibit the dissolution of manganese element and the formation of irreversible products. For the anode and electrolyte, uniform pore size distribution and lower de-solvation energy accelerate the migration and charge transfer of $\mathrm{Zn}^{2+}$. The HCCE has higher ionic conductivity, can stabilize the zinc stripping/deposition process and inhibit the corrosion as well as the growth of zinc dendrites, thus obtaining good electrochemical performance. This discovery may bring profound impacts toward the development of high-performance aqueous rechargeable battery by providing a facile and effective strategy for life cycle improvement.

Acknowledgements This work was supported by National Natural Science Foundation of China (Grant Nos. 51972346, 51932011, 51922038, and 51672078), Hunan Outstanding Youth Talents (No. 2019JJ20005), the Program of Youth Talent Support for Hunan Province (2020RC3011) and Innovation-Driven Project of Central South University (No. 2020CX024).

Open Access This article is licensed under a Creative Commons Attribution 4.0 International License, which permits use, sharing, adaptation, distribution and reproduction in any medium or format, as long as you give appropriate credit to the original author(s) and the source, provide a link to the Creative Commons licence, and indicate if changes were made. The images or other third party material in this article are included in the article's Creative Commons licence, unless indicated otherwise in a credit line to the material. If material is not included in the article's Creative Commons licence and your intended use is not permitted by statutory regulation or exceeds the permitted use, you will need to obtain permission directly from the copyright holder. To view a copy of this licence, visit http://creativecommons.org/licenses/by/4.0/.

Supplementary Information The online version contains supplementary material available at (https://doi.org/10.1007/ s40820-021-00595-6).

\section{References}

1. N. Zhang, X. Chen, M. Yu, Z. Niu, F. Cheng et al., Materials chemistry for rechargeable zinc-ion batteries. Chem. Soc. Rev. 49(13), 4203-4219 (2020). https://doi.org/10.1039/C9CS0 0349E

2. J. Zhou, L. Shan, B. Tang, S. Liang, Development and challenges of aqueous rechargeable zinc batteries. Sci. Bull. 65, 3562-3584 (2020). https://doi.org/10.1360/TB-2020-0352

3. X. Liu, F. Yang, W. Xu, Y. Zeng, J. He et al., Zeolitic imidazolate frameworks as $\mathrm{Zn}^{2+}$ modulation layers to enable dendrite-free Zn anode. Adv. Sci. 7(21), 2002173 (2020). https:// doi.org/10.1002/advs.202002173

4. H. Pan, Y. Shao, P. Yan, Y. Cheng, K.S. Han et al., Reversible aqueous zinc/manganese oxide energy storage from conversion reactions. Nat. Energy 1(5), 16039 (2016). https://doi. org/10.1038/nenergy.2016.39

5. H. Jia, Z. Wang, B. Tawiah, Y. Wang, C.Y. Chan et al., Recent advances in zinc anodes for high-performance aqueous $\mathrm{Zn}$ ion batteries. Nano Energy 70, 104523 (2020). https://doi. org/10.1016/j.nanoen.2020.104523

6. J. Huang, J. Zhou, S. Liang, Guest preintercalation strategy to boost the electrochemical performance of aqueous zinc ion battery cathoodes. Acta Phys. Chim. Sin. 37, 2005020 (2021). https://doi.org/10.3866/PKU.WHXB202005020 
7. Y. Liu, C. Li, J. Xu, M. Ou, C. Fang et al., Electroactivationinduced spinel $\mathrm{ZnV}_{2} \mathrm{O}_{4}$ as a high-performance cathode material for aqueous zinc-ion battery. Nano Energy 67, 104211 (2020). https://doi.org/10.1016/j.nanoen.2019.104211

8. W. Zhang, S. Liang, G. Fang, Y. Yang, J. Zhou, Ultra-high mass loading cathode for aqueous zinc-ion battery based on graphene wrapped aluminium vanadate nanobelts. NanoMicro Lett. 11(1), 69 (2019). https://doi.org/10.1007/s4082 0-019-0300-2

9. H. Li, L. Ma, C. Han, Z. Wang, Z. Liu et al., Advanced rechargeable zinc-based batteries: Recent progress and future perspectives. Nano Energy 62, 550-587 (2019). https://doi. org/10.1016/j.nanoen.2019.05.059

10. J. Ming, J. Guo, C. Xia, W. Wang, H.N. Alshareef, Zinc-ion batteries: Materials, mechanisms, and applications. Mater. Sci. Eng. R 135, 58-84 (2019). https://doi.org/10.1016/j. mser.2018.10.002

11. M. Song, H. Tan, D. Chao, H.J. Fan, Recent advances in Znion batteries. Adv. Funct. Mater. 28(41), 1802564 (2018). https://doi.org/10.1002/adfm.201802564

12. X. Pu, B. Jiang, X. Wang, W. Liu, L. Dong et al., High-performance aqueous zinc-ion batteries realized by MOF materials. Nano-Micro Lett. 12(1), 152 (2020). https://doi.org/10.1007/ s40820-020-00487-1

13. D. Chao, C. Zhu, M. Song, P. Liang, X. Zhang et al., A highrate and stable quasi-solid-state zinc-ion battery with novel 2D layered zinc orthovanadate array. Adv. Mater. 30(32), 1803181 (2018). https://doi.org/10.1002/adma.201803181

14. W. Xu, Y. Wang, Recent progress on zinc-ion rechargeable batteries. Nano-Micro Lett. 11, 90 (2019). https://doi. org/10.1007/s40820-019-0322-9

15. S. Guo, L. Qin, T. Zhang, M. Zhou, J. Zhou et al., Fundamentals and perspectives of electrolyte additives for aqueous zinc-ion batteries. Energy Storage Mater. 34, 545-562 (2021). https://doi.org/10.1016/j.ensm.2020.10.019

16. T. Zhang, Y. Tang, S. Guo, X. Cao, A. Pan et al., Fundamentals and perspectives in developing zinc-ion battery electrolytes: a comprehensive review. Energy Environ. Sci. 13, 4625-4665 (2020). https://doi.org/10.1039/D0EE02620D

17. F. Wang, O. Borodin, T. Gao, X. Fan, W. Sun et al., Highly reversible zinc metal anode for aqueous batteries. Nat. Mater. 17(6), 543-549 (2018). https://doi.org/10.1038/s4156 3-018-0063-z

18. J. Zhao, Y. Li, X. Peng, S. Dong, J. Ma et al., High-voltage Zn/ $\mathrm{LiMn}_{0.8} \mathrm{Fe}_{0.2} \mathrm{PO}_{4}$ aqueous rechargeable battery by virtue of "water-in-salt" electrolyte. Electrochem. Commun. 69, 6-10 (2016). https://doi.org/10.1016/j.elecom.2016.05.014

19. J. Zhao, J. Zhang, W. Yang, B. Chen, Z. Zhao et al., "Waterin-deep eutectic solvent" electrolytes enable zinc metal anodes for rechargeable aqueous batteries. Nano Energy 57, 625-634 (2019). https://doi.org/10.1016/j.nanoen.2018.12.086

20. J. Shin, J. Lee, Y. Park, J.K. Choi, Aqueous zinc ion batteries: focus on zinc metal anodes. Chem. Sci. 11, 2028-2044 (2020). https://doi.org/10.1039/D0SC00022A
21. M. He, K. Fic, E. Frackowiak, P. Novak, E.J. Berg, Influence of aqueous electrolyte concentration on parasitic reactions in high-voltage electrochemical capacitors. Energy Storage Mater. 5, 111-115 (2016). https://doi.org/10.1016/j. ensm.2016.06.001

22. D. Shanbhag, K. Bindu, A.R. Aarathy, M. Ramesh, M. Sreejesh et al., Hydrothermally synthesized reduced graphene oxide and Sn doped manganese dioxide nanocomposites for supercapacitoes and dopamine sensors. Mater. Today Energy 4, 66-74 (2017). https://doi.org/10.1016/j.mtener.2017.03.006

23. A.P.D. Balan, P. Pushpaletha, Metal supported and metal ion exchanged catalysts from palygorskite for acetylation reaction. Indian J. Chem. 57A, 649-654 (2018)

24. W. Wang, A. Wang, 2-palygorskite nanomaterials: structure, properties, and functional applications. Nanomater. Clay Miner. (2019). https://doi.org/10.1016/B978-0-12-81453 3-3.00002-8

25. S.C. Peng, C.H. Huang, T.H. Chen, Y.S. Yang, J.Q. Wang, The adsorption of $\mathrm{Zn} \sim(2+)$ on palygorskite and the optimization of the adsorption technological conditions. Acta Petrologica Et Mineralogica 23(3), 282-286 (2004). https://doi.org/10.1007/ BF02873097

26. M. Suárez, E. Garcia, FTIR spectroscopic study of palygorskite: influence of the composition of the octahedral sheet. Appl. Clay Sci. 31(1-2), 154-163 (2006). https://doi. org/10.1016/j.clay.2005.10.005

27. H. Chen, A. Zhong, J. Wu, J. Zhao, H. Yan, Adsorption behaviors and mechanisms of methyl orange on heat-treated palygorskite clay. Ind. Eng. Chem. Res. 51(43), 14026-14036 (2012). https://doi.org/10.1021/ie300702j

28. V. Bekiari, G. Panagopoulos, D. Papoulis, D. Panagiotaras, Use of halloysite nanotubes to reduce ammonium concentration in water and wastewaters. Mater. Res. Innov. 21, 313-319 (2017). https://doi.org/10.1080/14328917.2016.1215079

29. C.V. Lazaratou, D. Panagiotaras, M. Georgios Panagopoulos, D. Papoulis. Pospisil, Ca treated palygorskite and halloysite clay minerals for ferrous iron $\left(\mathrm{Fe}^{2+}\right)$ removal from water systems. Environ. Thchnol. Innov. 19, 100961 (2020). https://doi. org/10.1016/j.eti.2020.100961

30. M. Xia, J. Nie, Z. Zhang, X. Lu, Z.L. Wang, Suppressing selfdischarge of supercapacitors via electrorheological effect of liuqid crystals. Nano Energy 47, 43-50 (2018). https://doi. org/10.1016/j.nanoen.2018.02.022

31. B. Badu, A. Balducci, Self-discharge of lithium-ion capacitors. J. Power Sources Adv. 5, 100026 (2020). https://doi. org/10.1016/j.powera.2020.100026

32. Z. Wang, X. Chu, Z. Xu, H. Su, C. Yan et al., Extremely low self-discharge solid-state supercapacitors via the confinement effect of ion transfer. J. Mater. Chem. A 7(14), 8633-8640 (2019). https://doi.org/10.1039/C9TA01028A

33. K. Ragavendran, H. Xia, P. Mandal, A.K. Arof, Jahn-Teller effect in $\mathrm{LiMn}_{2} \mathrm{O}_{4}$ : influence on charge ordering magnetoresistance and battery performance. Phys. Chem. Chem. Phys. 19(3), 2073-2077 (2017). https://doi.org/10.1039/c6cp07289e

34. T. Liu, A. Dai, J. Lu, Y. Yuan, Y. Xiao et al., Correlation between manganese dissolution and dynamic phase stability 
in spinel-based lithium-ion battery. Nat. Commun. 10(1), 4721 (2019). https://doi.org/10.1038/s41467-019-12626-3

35. C. Zhan, J. Lu, A.J. Kropf, T. Wu, A.N. Jansen et al., Mn (II) deposition on anodes and its effects on capacity fade in spinel lithium manganate-carbon systems. Nat. Commun. 4, 2437 (2013). https://doi.org/10.1038/ncomms3437

36. C.F. Bischoff, O.S. Fitz, J. Burns, M. Bauer, H. Gentischer et al., Revealing the local $\mathrm{pH}$ value changes of acidic aqueous zinc ion batteries with a manganese dioxide electrode during cycling. J. Electrochem. Soc. 167(2), 020545 (2020). https:// doi.org/10.1149/1945-7111/ab6c57

37. W. Sun, F. Wang, S. Hou, C. Yang, X. Fan et al., $\mathrm{Zn} / \mathrm{MnO}_{2}$ battery chemistry with $\mathrm{H}^{+}$and $\mathrm{Zn}^{2+}$ coinsertion. J. Am. Chem. Soc. 139(29), 9775-9778 (2017). https://doi.org/10.1021/ jacs.7b04471

38. T. Abe, H. Fukuda, Y. Iriyama, Z. Ogumi, Solvated Li-ion transfer at interface between graphite and electrolyte. J. Electrochem. Soc. 151(8), A1120-1123 (2004). https://doi. org/10.1149/1.1763141

39. C. Yan, H.R. Li, X. Chen, X.Q. Zhang, X.B. Cheng et al., Regulating the inner Helmholtz plane for stable solid electrolyte interphase on lithium metal anodes. J. Am. Chem. Soc. 141(23), 9422-9429 (2019). https://doi.org/10.1021/ jacs.9b05029

40. K. Xu, A. von Cresce, U. Lee, Differentiating contributions to "ion transfer" barrier from interphasial resistance and $\mathrm{Li}^{+}$ desolvation at electrolyte/graphite interface. Langmuir 26(13), 11538-11543 (2010). https://doi.org/10.1021/la1009994

41. D. Kundu, S.H. Vajargah, L. Wan, B. Adams, D. Prendergast et al., Aqueous vs nonaqueous $\mathrm{Zn}$-ion batteries: consequences of the desolvation penalty at the interface. Energy Environ. Sci. 11(4), 881-892 (2018). https://doi.org/10.1039/C8EE0 $0378 \mathrm{E}$

42. X. Xie, S. Liang, J. Gao, S. Guo, J. Guo et al., Manipulating the ion-transference kinetics and interface stability for highperformance zinc metal anode. Energy Environ. Sci. 13(2), 503-510 (2020). https://doi.org/10.1039/C9EE03545A

43. L.E. Blanc, D. Kundu, L.F. Nazar, Scientific challenges for the implementation of $\mathrm{Zn}$-ion btteries. Joule 4(4), 771-799 (2020). https://doi.org/10.1016/j.joule.2020.03.002
44. P. Oberholzer, E. Tervoort, A. Bouzid, A. Pasquarello, D. Kundu, Oxide versus nanoxide cathode materials for aqueous Zn batteries: an insight into the charge storage mechanism and consequences thereof. ACS Appl. Mater. Interfaces 11(1), 674-682 (2019). https://doi.org/10.1021/acsami.8b16284

45. Z. Zhao, J. Zhao, Z. Hu, J. Li, J. Li et al., Long-life and deeply rechargeable aqueous $\mathrm{Zn}$ anodes enabled by a multifunctional brightener-inspired interphase. Energy Environ. Sci. 12(6), 1938-1949 (2019). https://doi.org/10.1039/C9EE00596J

46. Y. Wen, J. Cheng, L. Zhang, X. Yan, Y. Yang, The inhibition of the spongy electrocrystallization of zinc from doped flowing alkaline zincate solutions. J. Power Sources 193(2), 890894 (2009). https://doi.org/10.1016/j.jpowsour.2009.04.047

47. C.J. Lan, C.Y. Lee, T.S. Chin, Tetra-alkyl ammonium hydroxides as inhibitors of $\mathrm{Zn}$ dendrite in $\mathrm{Zn}$-based secondary batteries. Electrochim. Acta 52(17), 5407-5416 (2007). https:// doi.org/10.1016/j.electacta.2007.02.063

48. H. Inoue, M. Kurosaki, S. Nohara, Deposition of zinc in polymer hydrogel electrolyte. J. Electrochem. Soc. 4, 396 (2008). https://doi.org/10.1016/jelectacta.2007.02.063

49. J. Xu, W. Wang, B. Mu, A. Wang, Effects of inorganic sulfates on the microstructure and properties of ion- exchange treated palygorskite clay. Colloids and Surfaces A: Physicochem. Eng. Aspects 405(5), 59-64 (2012). https://doi.org/10.1016/j.colsu rfa.2012.04.037

50. H. Yang, Z. Chang, Y. Qiao, H. Deng, X. Mu et al., Constructing a super-saruteted electrolyte front surface for stable rechargeable aqueous zinc batteries. Angew. Chem. Int. Ed. 59(24), 9377-9381 (2020). https://doi.org/10.1002/ ange.202001844

51. R. Dong, Y. Liu, X. Wang, J. Huang, Adsorption of sulfate ions from aqueous solution by surfactant-modified palygorskite. J. Chem. Eng. Data 56(10), 3890-3896 (2011). https:// doi.org/10.1021/je200544n

52. H. Qiu, X. Du, J. Zhao, Y. Wang, J. Ju et al., Zinc anode-compatible in-situ solid electrolyte interphase via cation solvation modulation. Nat. Commun. 10(1), 1-12 (2019). https://doi. org/10.1038/s41467-019-13436-3 